1937

\title{
The Diagnosis of hyperthyroidism
}

William J. Rosenbladt

University of Nebraska Medical Center

This manuscript is historical in nature and may not reflect current medical research and practice. Search PubMed for current research.

Follow this and additional works at: https://digitalcommons.unmc.edu/mdtheses

Part of the Medical Education Commons

\section{Recommended Citation}

Rosenbladt, William J., "The Diagnosis of hyperthyroidism" (1937). MD Theses. 543.

https://digitalcommons.unmc.edu/mdtheses/543

This Thesis is brought to you for free and open access by the Special Collections at DigitalCommons@UNMC. It has been accepted for inclusion in MD Theses by an authorized administrator of DigitalCommons@UNMC. For more information, please contact digitalcommons@unmc.edu. 


\section{THE DIAGNOSIS OF HYPERTHYROIDISM \\ William J. Rosenbladt}

\section{SENIOR THESIS}

PRESENTED TO THE COLLEGE OP MEDICINE

UNIVERSITY OF NEBRASKA

ONAFA

1937 
TABIE OF CONTINTS

1

I Introduction . . . . . . . . . . I

II Classification of Hyperthyroidism .... 9

III Age . . . . . . . . . . 15

IV $\quad \operatorname{sex} . . . . . . . . . . .18$

V The Thyroid Gland ..........20

VI Signs and Symptoms Related to the Eye............25

VII The Efrect of Hyperthyroidism Upon the Skin and its Accessory Structures . . 35

VIII Nerrousness and Tremor . . . . . . . 40

IX The Thyroid Cardio-Vascular System . . . . 43

$x$ Disorders of the Gastro-Intestinal Tract. . 50

XI Muscular System in Hyperthyroidism . . . . 58

XII Genito-Urinary Disturbances . . . . . 60

XIII The Blood Picture in Hyperthyroidism . . . 62

XIV The Value of Basal Metabolic Rate in Diagnosis . . . . . . . . 70

XV Miscellaneous Tests and Laboratory Findings in Fyperthyroidism . . . . 76

XVI Summary . . . . . . . . . 80 
INTRODUCTION

Hyperthyroidism is a clinical entity which has engaged the scientific interest and fascination of myriads of investigators for over a century. It has come to be looked upon as a condition resulting both from thyroid dysfunction and outside influences and may occur with or without clear cut signs and symptoms. A multitudeness literature has accumulated since the first description by Caleb Hillier Parry (72) in 1825. He described elght cases of enlargement of the thyroid gland with exophthalmos and palpitation of the heart. The first case was observed by him in 1786. Ten years following his report, Sir Robert Graves ( 29 ) described the cases of four patients, three of which vere females, suffering from enlargement of the thyroid gland, palpitation of the heart, a sense of fulness in the throat, nervousness, weakness on exertion, loss of weight and exophthalmos. All of these patients presented loud heart sounds. He noted that this symptom complex was present in paroxysms accompanied by periods of remission. This constitutes the rirst complete description to which we have access and it is relatively accurate as we know hyperthyroidism today. 
In his original article he states, "I have lately seen three cases of violent and long continued palpitations in females, in each of which the same peculiarity presented itself, viz., enlargement of the thyroid gland; the size of this gland, at all times considerably greater than natural, was subject to remarkable veriations in every one of these patients. When the palpitations were violent the gland used notably to swell and become distended, having all the appearance of being increased in size in consequence of an interstitial and sudden effusion of fluid into its substance. The swelling imnediately began to subside as the violence of the paroxysm of palpitation decreased, and during the intervals the size of the gland remained stationary. Its increase of size and the variations to which it was liable had attracted forcibly the attention both of the patients and their friends. There was not the slightest evidence of anything like inflammation of the gland........... The palpitations have in all lasted considerably more than a year, and with such violence as to be at times exceedingly distressing, and yet there seems no certain grounds for concluding that organic disease of the heart exists............. Another fact, well worthy of notice, is that females liable to attacks of palpitations almost invariably complain of a sense of fulness, referred to 
the throat, and exactly corresponding to the situation of the thyroid. This sensation only continues while the paroxysm of palpitation lasts, and frequently is so urgent as forcibly to attract the patient's notice, who now complains of its inducing a sense of suffocation."

In another case of a girl, age twenty, he noticed that, "After she had been in this nerrous state about three months, it was observed that her pulse had become singularly rapid. This rapidity existed without any apparent cause, and was constant, the pulse being never under 120, and often much higher. She next complained of weakness on exertion, and began to look pale and thin. Thus she continued for a year, but during this time she manifestly lost ground on the whole, the rapidity of the heart's action having never ceased. It was now observed that the eyes assumed a singular appearance, for the eyeballs were apparently enlarged, so that when she slept or tried to shut her eyes, the lids were incapable of closing. When the eyes were open, the white sclerotic could be seen, to a breadth of several lines, all round the cornea."

The same symptom complex was described in 1840 by Basedow and in 1859 by Charcot. ( 13 ) The cause for this condition was discussed by Sir Victor Horsley in 1885 ( 33 ) and in 1886 by Mobius. ( 54 ) The latter was 
the first to relate the thyroid gland to the pathogenesis of exophthalmic goiter and ( $23 a$ ) he contended that all forms of this disorder depended upon the poisoning of the body by a copious production of a harmful secretion from the thyroid gland. It was not until 1911 that Plummer (65) differentiated the condition described by these men which we now call exophthalmic goiter or Graves' disease from the hyperthyroidism of toxic adenoma.

There have been numerous attempts to reproduce the clinical pieture of hyperthyroidism experimentally, none of which have been entirely successful ( 26$)$ and as a result there are many features which we recognize clinically as signs or symptoms which aid us in the clinical diagnosis of this aisease which have not been entirely explained.

It must be borno in mind that in diagnosis the subjective evidences of the patient's own story are the least dependable probably of all the material available. Honest losses of memory coupled with the suppression of facts and with frank mis-statements intended to mislead are all vitiating factors. While the subjective data are the least controlled, serious error may also appear indirectly in the laboratory measurements. Both the subjective clinical evidence and the objective laboratory data may be unreliable and yet, on the other hand, both may be essential to the resolution of a diagnostic problem. 
One other matter presents itself for careful consideration. The presence of organic or functional disease of an endocrine gland in an individual patient, does not preclude the presence of other disease conditions unassociated directly with it. In fact, very many endocrine cases will demonstrate the presence of an intercurrent disease which may equal or even exceed in importance the glandular derangement. Since these superimposed conditions may all influence, in some measure, the various individual data that make up the disease picture, due account must be given them.

As a factor pertinent to the diagnosis of hyperthyroidism, it is not uncommon throughout the literature to find various features which have been considered as cardinal signs and symptoms in this endocrine dysfunction. one author (70-b) considers as the cardinal signs: enlargement of the thyroid gland, tachycardia, tremor of the extremities, exophthalmos or protrusion of the eyeballs and an elevation of the basal metabolic rate. Phillips, of the crile clinic in Cleveland, (64-a) has the same idea with the exclusion of the basal metabolic rate. Jackson (35-a) considers Plummer's test (Page 58) as one of the four most important diagnostic points in exophthalmic goiter and considers it also of great prognostic importance. It is of interest to note that not 
infrequently an investigator will consider one sign or symptom as boing relatively diagnostic and that that sign or symptom is oft times within the realm of that investigator's speciality. cookson ( 16 ) feels that the most characteristic picture in toxic goiter is that in which the heart shows a slight general enlargement more especially to the left with an obliteration of the pulmonary bay so that the heart has a ham-shaped profile. Christie ( $14 a$ ) had the same idea ten years earlier and suggested also the importance of palpable thrills and audible murmurs in thyrotoxicosis. Clute and Adams ( 15 ) would be very hesitant of making a diagnosis of hyperthyroidism in the absence of a tachycardia of 90 or more beats per minute.

In contrast to this attitude, one need not go far in his studies of the toxemia related to the thyroid gland to find many cases reported in which the thyrotoxicosis is masked and frequently some or all of the most striking features of hyperthyroidism, such as tachycardia, goiter, elevated besal metabolic rate and weight loss are absent. (49-a) Levine (46) studied many cases which were unrecognized theretofore by competent men and he based his diagnosis upon the general appearance of the patient; warm, moist, hyperemic and slightly pigmented skin; greater comfort in cold weather than in warm 
weather; brief attacks of diarrhea or vomiting; great loss of weight; alert, quick movements; often a peculiar stare, a tremor of the fingers, and at times transient glyoosurla.

The diagnosis of cases of hyperthyroidism may be a relatively simple thing if a majority of the signs and symptoms usually seen are present. On the other hand, the many cases which remain undiagnosed in early years and until the onset of toxic heart disease, remain as an admission on the part of the average practicioner and, in fact, many specialists, of the difficulty which is encountered and of the delicacies of observation necessary to arrive at a correct diagnosis of a large percentage of cases with hyperthyroidism. To add. to the increasingly complex system of diagnostic methods, many of which are of considerable value in hyperthyroid problems, is not the object of this paper. However, an attempt has been made to exhaust the literature available and eke from this voluminous labyrinth a simple summary and an evaluation of all of the diagnostic aids that present themselves. In addition to the literature, it has been my privilege to have available the charts of the hyperthyroid cases admitted to the University of Nebraska Hospital from 1930 to 1934 which total 155 in number. These have been analyzed 
during the last year and the results will be found in the body of this paper. The aids to diagnosis e.g., age, incidence, sex, etc.; the clinical signs and symptoms; and the various laboratory and clinical diagnostic tests have been considered. 


\section{CLASSIFICATION OF HYP HRTHYROIDISM}

The earliest recognization of a hyperthyroid syndrome was that of Parry in 1825. (72) This was a description of eight cases of exophthalmic goiter, a clinical entity which we recognize today as being one of the most common causes of hyperthyroidism. This makes it convenient to distinguish between exophthalmic goiter and all other forms of toxic goiters. Besides being more common, it is manifested, as a rule, as a well defined disease which is fairly easy to diagnose, especially in the advanced cases. ( 38 )

There have been a number of attempts made in establishing and simplifying an acceptable classification for toxic reactions whose origin is apparently a thyroid dysfunction. Probably the most widely accepted classification today is that which is used by cecil. ( 12 ) This elassification is one which has been recommended by the Committee on Classification of the American Association of Study of Goiter. This includes:

Type 1. Nontoxic diffuse goiter

Type 2. Toxic diffuse goiter

Type 3. Nontoxic nodular goiter

Type 4. Toxic nodular goiter 
"This is a simple grouping based on easily recognizable signs and symptoms but it has not yet been generally adopted." Reinhoff ( 71 ) believes that upon examination of the thyroid gland of the patient and the discovery of a nodular enlargement, it is impossible to distinguish clinically to which group these nodules belong, neoplasm or adenoma. He believes that the above classification is the only classification which is logically and scientifically correct and upon which the clinical diagnosis can be based. He, therefore, in reality has but two classifications of goiter; that is, the nodular and the diffuse. Either of which may have an associated hyperthyroidism depending upon the accompanying signs and symptoms. He prefers to reject the terms toxic adenoma and hyperfunctioning goiter, believing them to be misleading and incorrect. Marine ( 51 ) considers that hyperthyroidism is but an entity, a disease of the nerrous system, in which the visceral nervous system is most prominently involved and which is characterized by a profound disturbance of the regulatory control and functional interactions of all organ activities, its most prominent manifestations being increased metabolism of thyroid origin, general asthenia, tachycardia and moderate thyroid enlargement. He insists that it is necessary 
to look beyond the thyroid for the primary disturbance. He admits that the disease may well be divided into acute and chronic forms, but prefers not to use such terms as toxic adenoma, adenomatous goiter with hyperthyroldism and thyrotoxicosis. Bram (.8) found the following pathological-therepeutic classification very useful. TOXIC

$\begin{array}{ll}\text { Toxic adenoma hyperthyroidism - Surgical } \\ \text { Diffuse adenomatosis } & \text { - Surgical } \\ \text { Puberty hyperplasia } & \text { - Non Surgical } \\ \text { Exophthalmic goiter } & \text { - Non Surgical }\end{array}$

Ashoff ( 1-A ) went further in his classification of exophthalmic goiter. His first sub-type consisted of exophthalmic goiter without the typical triad: exophthalmos, diffuse goiter and tremor. The second was that with cytologic progression to Basedow's thyroid. Engelbach ( 23-b ) uses synonymously the terms toxic nodular goiter, toxic adenoma, adenomatous goiter with hyperthyroidism, toxic non-symmetric goiter, toxic assymetrical goiter, toxic adenomatosis or adenoma. Hyperthyroidism has been divided by Plummer (65) into exophthalmic goiter and hyperfunctioning adenomatous goiter. He distinguishes the two by stating that in the latter, the basal metabolic rate is more nearly normal. While in exophthalmic goiter there 
are certain definite symptoms; the nervous phenomena and the eye symptoms. The nervous phenomena include purposeful but useless movement. The higher psychic processes are chaotic. Patients cannot explain why they laugh or cry. The eye phenomena consist of exophthalmos or protrusion of the eyeball and the stare which fluctuates with the nerrous phenomena.

From his previous work on the relationship of the symptoms and pathology of hyperthyroidism, he (66) concluded in 1928 that exophthalmic goiter and adenomatous goiter with hyperthyroidism were two distinct entities. He noted that the diffuse hypertrophy of the thyroid gland, as is seen in exophthalmic goiter, was not a part of the same disease process, as the localized hypertrophy which is seen in adenomatous goiter. Hyperfunction of the entire gland, he believes, results in the hyperthyroidism of exophthalmic goiter; while the hyperthyroidism of adenomatous goiter is the result of a localized reaction in the gland.

Other authors have relatively more simple classifications of hyperthyroidism. McCullagh ( 49 ) divided his unusual hyperthyroid cases according to the following:

1. Hyperthyroiaism in which symptoms and signs relating to one system are unusually 
prominent, thus producing a clinical picture which simulates a disease of a single system.

2. Hyperthyroidism in which one or more of the commonest symptoms or signs are absent.

3. Hyperthyroidism complicated by another condition which dominates the clinical picture.

The activated and non-activated or apethetic classification of hyperthyroidism is a product of Lahey. (43) In the former there are striking eye signs, stare, exophthalmos, usually enlarged firm thyroid, striking pulse rate and obvious tremor. The activated type is obvious to diagnosis and carries with it serious possibility of fatelity. In the latter the striking features are not present. They occur in older people and have, as a rule, no eye signs, a small thyroid, a pulse rate below 120 and the characteristic thrust of the apex beat is lacking.

It is of interest to note that none of the above classifications of hyperthyroidism have made any consideration for a type of the disease which occur vithout a pelpable or visible goiter. By definition ( 20 ) goiter is an enlargement of the thyroid body, causing a swelling in the front part of the neck. Tucker (78) 
Mocullagh, ( 49 ) Phillips, (64-b ) Clute and Adams ( 15 ) and others have described series of cases of hyperthyroidism in which there is no demonstrable goiter or thyroid enlargement. It would seem acceptable to have some division in the classification of this disorder which would also include these cases and segregate them from those with goiter. 
There may be considerable variation in the age at which hyperthyroidism appears. The various types of hyperthyroidism involved is undoubtedly an important factor. However, we must realize that this disease, being an endocrine disorder is subject, as a rule, to the same course as endocrine dysfunctions in general. There is a higher accumulation in the number of endocrine disorders during the adult years. The lack of recognition of these in earlier life is partly responsible. Knowing the increase in demand upon the endocrine glands by the reproductive factors, one may reason very logically that there are as many endocrinisms in adults as there are diseases of any non-endocrine system. The disturbances in the endocrine system prior to adolescence consist chiefly of the inactivities, while the hyper activities occur in an increasing number in the second, third and fourth decades of life. This is especially true of hyperthyroidism in which the largest percentage of cases occur after the age of thirty. (23-d) host authors agree that exophthalmic goiter is not concerned with age since the disease may develop at times ranging from the first to the eighth decades. ( $35-\mathrm{b})$ It is usually seen, however, during the years when sexual or 
active adult life is at a peak. (9-a) It has been seen at fourteen years ( 79 ) and at eighty-two years. (24) Jackson noted that the average age in this disease was twenty-six. (35-b) Hertzler and Reinhofe $(32-a)(70-c)$ agree very closely with him. A case of a fetus with congenital Graves' disease was reported in 1912 by Clifford White. ( 80 )

Boothby $(7-A)$ analyzed one thousand thirtysix cases of exophthalmic goiter at the Mayo Clinic and found that 61 per cent of the patients were under forty years, and 15 per cent over fifty years. 6 per cent were under twenty, 24 per cent between twenty and twentynine, 31 per cent between thirty and thirty-nine and 24 per cent between forty and forty-nine. Angelbach ( 23-f) found in his cases of exophthalmic goiter that three out of sixty-two cases were under twenty, twentyone occurred between twenty and thirty, seventeen between thirty and forty, sixteen between forty and fifty and five after fifty years.

The average age in the toxic nodular goiters is, as a rule, slightly above that of the exophthalmic type. Bram ( 8 ) found it to exist most frequently during midale age. In four hundred twenty-six cases of thyroid disease studied by Engelbach ( 23-e ) the diagnosis of nodular goiter with hyperthyrojdism was 
made in patients whose ages varied from twenty-four to sixty-nine years. Boothby $(7-\mathbb{A})$ found that in nodular goiter with hyperthyroidism, 78 per cent of the patients were over forty years.

In one hundred fifty-five cases of thyroid disease at the University of Nebraska from 1931 to 1934, twenty-seven were diagnosed as toxic diffuse goiter. I have found the average in these cases to be thirty-one years, and the span was from seventeen years to fiftythree years. There were forty-one cases of toxic nodular goiter with an average age of forty-one jears and the span in these cases ranged from twenty-three years in the youngest to sixty years in the oldest. 
SEX

The incidence of both exophthalmie goiter and toxic nodular goiter is in preponderance in the female. Ratios of from 10:1 to $2: 1$ have been reported. "A survey of the sex incidence in Boothby"s series of one thousand thirty-six cases of exophthalmic goiter showed that 82 per cent occurred in women and 18 per cent in men. A ratio of about 4.5 to 1 . No material difference was found in the symptoms or intensity of the discord in the two sexes." (7-A) Engelbach's series of sixty-two cases showed a ratio of less than 2 to 1. (23-f) The former is, of course, the more acceptable since in any report the larger the number of cases, the more accurate the statistics will be.

In his study of the toxic nodular goiters, Jackson (35-b) found a ratio of 7 to 1 with the preponderance again in favor of the females. The earlier writers believed that the reason for this disproportion was the close association between the genital functions and the thyroid gland, indicated by the slight enlargement often seen during menstruation, and still more pronounced during pregnancy. The goiters of the adolescent girls are so closely associated with the advent of the menses that a relationship must be assumed. 
The whole endocrine system is upset periodically at the menstrual periods and during pregnancy, and its significance we cannot now estimate.

It is of passing interest that not only the hyperthyroid cases are more prevalent in women, but this fact holds true in practically all diseases of the thyroid gland. 
THE THYROID GLAND

The thyroid gland has been held responsible for hyperthyroidism since its first recognized enlargement associated with toxic symptoms was reported in 1825. The most important and contributory eridences of goiter are revealed by inspection, palpation and auscultation. These examinations, however, are of limited value, as will be pointed out later, in the diagnosis of thyroid disorders, whether it be simple goiter or hyperthyroidism. As is true of so many details of diagnosis, a manifest thyroid enlargement is merely contributory and confirmatory evidence of the possibility of hyperthyroidism.

In a normal individual, no evidence of the presence of a thyroid gland can be detected by simple inspection. In experienced hands, the gland in an average neck is bearly palpable. If it may be palpated with ease, chances are it is slightly enlarged. We are possessed of no satisfactory method by which enlargement can be determined. Palpation may be interfered with by the neck muscles, a generous deposit of subcutaneous adipose tissue, or the fact that the thyroid is substernal.

A normal thyroid is soft in consistency which 
may also be true of goiter, but the rule is for an enlargement to be represented by more or less firm tissue. The duration of a thyroid enlargement has its bearing upon the glandular morphology. Toxic goiters are frequently sensitive to manipulation. In the severe case, they may be as sensitive as a thyroiditis. The mobility of the gland should also be observed. Not infrequently non-toxic goiters are freely movable under the overlying muscles while acutely toxic goiters may be quite firmly fixed, and berely movable upon deglutition.

Upon inspection of the neck in cases of hyperthyroidism from nodular goiter, we see asymmetrical enlargement of the thyroid gland with one or more nodular prominences. In diffuse toxic goiter enlargement differs markedly from the above type in that it is symmetrical and smooth. In either case, however, it will be pointed out, no visible enlargement may be present. There may be a visible prominence and pulsation of the blood vessels of the neck in acutely toxic cases.

A study of the anatomical structures of the neck indicates that the thyroid gland may undergo a fairly sizable enlargement and yet conceal itself amid the soft structures of the neck behind the sternocleido-mastoid, sterno-hyoid or sterno-thyroid museles and the overlying subcutaneous adipose tissue. It is 
possible also from an anatomical standpoint for the glands to enlarge posteriorly and wrap itself around the trachea or even extend into the superior mediastinum. In such a case one might expect a definite thickening of the thyroid isthmus to be palpable. A swelling of the neck muscles might inhibit palpation of a rising gland from the retromanubral region upon deglutition. These racts make it obvious that the physician who will make his diagnosis of hyperthyroidism only upon the presence of a demonstrable goiter, may frequently fail to arrive at the correct diagnosis.

In a toxic diffuse goiter, the lobes retain a more or less pear shape, are firm or occasionally soft and the surface has a granular feel to the palpating finger. There are times when a thrill is detectable. ( 83 ) ( 64-a) The entire gland may possess an expansile pulsation almost like that of an aneurysm. (64-a)

In Rowe's ( 73 ) investigations of hyperthyroidism, 34 per cent of the series showed thyroid enlargement while in two-thirds of the cases which were proven to be thyroid dysfunction, there is no such enlargement. Clute and Adams found that over 50 per cent of their cases lacked a demonstrable enlargement of the thyroid gland. ( 15 ) In spite of this fact, if other features - of the disease are present, it should not deter one 
from making the diagnosis of toxic thyroid and instigating proper methods of therapy. (49) Tucker (78) in his work at the Cleveland Clinic has had many cases of hyperthyroidism in which the diagnosis has been missed by competent physicians because of the lack of a thyroid enlargement which is detectable upon physicial examination. He states that, "In our experience we have not infrequently seen cases of unquestioned hyperthyroidism in which by any clinical method of estimation of the size of the gland, it was not found to be enlarged --being neither visible nor palpable before or during deglutition."

The superior thyroid artery can often be felt to pulsate much more vigorously than in the normal gland. (64-a ) The presence of a systolic bruit over the upper poles is detectable in most instances even in small glands and is of great diagnostic importance providing there is no systolic murmur present over the aortic area. The administration of iodine may cause the polar bruit to diminish in intensity or even disappear. ( 83 )

Pressure symptoms due to impingment upon the trachea, esophagus or blood vessels of the neck are relatively uncommon in the hyperthyroid cases resulting from toxic diffuse goiter, but occur rather frequently 
in nodular goiter. This is not so much because of the size of the goiter as it is to the location of a nodule. If this nodule is post-tracheal, substernal or intrathoracic such symptoms are almost bound to appear. ( 83 ) H. A. Freund and W. B. Cooksey (25) have observed that cases of thyrotoxicosis in elderly persons actually develop without discernible goiter. None of their reported cases had goiter nor could adenomatous tissue be demonstrated at operation. The goiter of toxic adenoma is often present for years before the onset of symptoms. ( 8 )

These facts show the importance which should be placed upon the presence of toxic symptoms in patients suspected of hyperthyroiaism, be there goiter or not. 
SIGNS AND SYIPTOMS REIATED TO THE EYE

Here we need consider only the type of hyperthyroidism which is associated with exophthalmic or toxic goiter. A mass of literature has been written on the various phases of exophthalmos, but the primary interest of this section is only that of its diagnostic value. It is distinguished from ordinary prominence of the eyes by history, peculiar brightness, appearance of the sclera between the upper lid and the corna, infrequent winking and lagging of the upper lid. It should be borne in mind that occasionally only one eye is involved. This $(35-\mathrm{c})$ is true of 10 per cent of the cases. These cases are easily differentialed from tumor and arterior-venous aneurysm of the orbit.

This condition of the eye was noted and recorded by Parry (Page 1 ) and by Graves (Page 3 ) and others. The term exophthalmic goiter is very frequently used but is a misnomer since the disease can occur without perceptable exophthalmos and without perceptable enlargement of the thyroid gland. This, then, would probably suggest that some symptoms are present which are not a result of a pure hyperthyroidism, but that the initial cause of the disease is probably beyond the thyroid gland itself. Phillips ( 64-c) believes that the oye signs 
present some of the most characteristic features of the disease. He has seen exophthalmos so extreme that the eye ball is displaced from the socket. He also refers to a marked pigmentation of the eyelids as a diagnostic feature.

On the other hand, the absence of exophthalmos is probably the cause for the failure in diagnosis of many otherwise typical cases. When exophthalmos is absent, as is very frequently true in the early stages of the disease, there may be other signs relative to the eye which close inspection will reveal, such as, slight prominence of the eyes, a characteristic staring expression, lid-lag, widening of the palpebrel fissure and others which will be described later. The eye findings in exophthalmic goiter are probably next in importance to the thyroid gland itself. They reveal a number of peculiarities which are almost pathognomic of the disease, especially when a number of the signs are present. Bram ( 9-b) has made rather extensive study of the symptoms related to the eye. The number and the degree or the various signs is no indication of the severity and the duration of the disease. $(9-b)(35-c)$ We know from reports in the literature to which we will refer later that the disease may be diagnosed before the eyes are obviously effected.- Sooner or later, though, we may 
expect to find the onset of mild eye symptoms and eventually in most cases a definite exophthalmos.

As a rule, the earliest eye symptoms are characterized by peculiar stare which is present only upon mental activity especially in conversation. The friends or relatives of the patient may become aware of this peculiarity and urge the advice of a physician. This stare usually progresses slowly and gradually until it eventually may change the expression of the individual. It bears no relationship to the age at which the disease manifests itself. $(9-b)$

During the first three months of the disease, exophthalmos is present only in 50 per cent of the cases, ( $35-\mathrm{c})$ while 65 to 85 per cent will ultimately develop the condition. (9-b)

A widening of the palpebral fissure has been described and is referred to by Bram $(9-b)$ as Dalrymple's sign and by Engelbach (23-g) as Stellwag's sign. The original reference is not available and no correction can be made. However, there apparently has been some misinterpretation by one or the other author. Reinhoff ( 70-d ) refers to it as Dalrymple's sign. The condition consists of a retraction of the upper lid so that there is a resulting unusual separating between the two lids. This causes the ocular fissure to widen, revealing a ring of sclera between the lids and the edge 
of the cornea, which results in a peculiar stare. The condition may be present in various degrees, at times revealing the sclera above the cornea only or below the cornea only, or as is usually the case in more advanced cases, an entire ring of sclera is visible. Mccullagh (49) reported the case of, "A women who complained only of widening of the left palpebral fissure. No other evidence of hyperthyroidism could be demonstrated during two and a half months of observation, at the end of which time visible and measurable evidences of involvement of the opposite palpebral fissure began to be apparent. The basal metabolic rate at this time was plus 15 per cent. Although there was only questionable enlargement of the thyroid gland, thyroidectomy was performed, following which the eye signs disappeared."

The infrequent blinking or winking is so characteristic of the disease in patients who have positive signs referred to the eye, that as a rule, only one case need be observed in order to elicit it. Again, Bram ( 9-b) and Ingelbach (23-g) disagree. The former refers to this as Stellwag's sign, while the latter prefers to call it Dalrymple's sign. At any rate, the blinking in exophthalmic goiter cases occurs at an interval of a minute or more. This is true in 30 per cent to 50 per cent of the cases. (70-d) We know 
that normally blinking occurs on an average of two or three times per minute. The latter author explains that the condition may be caused by dryness of the eyeballs and cornea which often results in keratitis and ulcers. On the other hand, he has seen cases which have an excessive lacrimation corresponding to the unusual sweating of the skin and secretions of, the mucous membrane, such as salivation and leucorrhea, Von Graefe's ( 78 A ) sign may be a very valuable aid in the early diagnosis of the disease. It consists of a lagging of the upper lid when the eyeball is rolled downward. Normally, when this test is made, the upper lid will move in perfect relationship with the eyeball. When the sign is positive, the upper lid is delayed as it makes an attempt to follow the eye downward, or it may stop in its motion downward allowing the eyeball to continue moving alone. Occasionally cases are seen in which the upper lid fails to move at all. (9-b) The symptom is not present in all cases of hyperthyroidism on an exophthalmic basis, but when it is present, one may fairly accurately predict that exophthalmos will follow. To elicit this sign most accurately the lid should be made to move very slowly. Here at times a positive sign related to the widening of the ocular iissure may be observed in cases in which 
it is not positive, with the eyeball in its primary position. Normally the margin of the upper lid will correspond exactly to the upper margin of the cornea. In the cases just referred to there may be a rim of sclera present between the two.

Mobius ( 54 ) described the failure of convergence associated with exophthalmos which is present in the largest percentage of cases. The patient is instructed to focus his eyes upon the examiner's finger. As the finger is moved towards the patient's nose, if the sign is positive, one eye will move laterally leaving the other eye focused on the finger. Normally, of course, both eyes will converge increasingly as the finger approaches the nose. There is a variation in the opinion of various investigators as to the inportance of this sign.

Lowy's sign was first described by him in 1905. It consists of mydriasis following the instillation of adrenalin which normally produces the opposite effect. ( $48 \mathrm{~A})$

Reisman ( 69 A) has described the bruit over the eyeball which can be heard at auscultation and sometimes palpated. Suker noted a deficient complementary fixation of the eye. ( 76 A ) (9-b) "After extreme lateral rotation of the eyes to the right or 
to the left with the head fixed and with fixation of an object at this point maintained for a second or two, on attempting to following this fixation point as it is rapialy swung into the median line, one or other of the eyes fails to follow its fellow in a complementary manner into proper convergence and for this point, when it is brought into the median line. Fither the right or the left eye makes a sudden rotation into the fixation with its fellow, but before it does so, an apparent divergent strabismus is manifested. Suker believes this phenomenon due to a dissociation in the functions of the sympathetic and the extra-ocular motor nerves of the eye, and perhaps also to exhaustion on extreme lateral rotation of the eye."

The pigmentation of the eyelid making a discolored ring around the orbit is referred to most frequently as the Jellinek-Teillais sign. It occurs in from 10 to 25 per cent of the cases of Graves disease. (9-b) Some authors believe that Clifford's sign, (9-b) or difficulty in everting the upper lid, is an almost constant sign. The many signs and observations which have been recorded represent keen diagnostic ability on the part of these men. Care must be taken that their value is not over-estimated. Most investigators agree that a definite exophthalmos is absent in a majority of the 
cases of Graves' disease when the patient visits his Doctor for the first time. Of fifty-two cases of this disorder, studied by Engelbach, (23-h) twenty-one had exophthalmos and thirty-one were free from positive ocular signs ordinarily associated with this disorder. Yung (83) found it present in 40 per cent of his cases. Engelbach quotes Boothby (23-i) stating that from the viempoint of easy diagnosis exophthalmos often an early symptom, is not present in from 20 per cent to 40 per cent of the cases at the time they first come under observation. In some cases, the disorder may be either cured or spontaneously run a course without the sign becoming manifest. The presence or absence of exophthalmos in these cases, then, depends somewhat upon the duration and activity of the hyperthyroidism. (23-i) On the other hand, although all the cases of Graves' disease do not have extreme exophthalmos, some of its associated signs are present in a sufficiently large percentage of cases to make the term exophthalmic goiter the most expressing and fitting. (23-j) Means and Richardson (52) in their series of one hundred and fifty unselected cases of exophthalmic goiter studied in the Massachusetts General Hospital, indicate that the presence of this condition is much more common than other writers would lead us to believe. 83 per cent of their patients 
had exophthalmos and 17 per cent were without ocular signs. Of this number 63 per cent had Von Graefe's sign and 35 per cent Mobius' ocular sign or exophthalmic goiter. Eight cases have been reported in which operation was followed by the onset of exophthalmos, even though the metabolic rate was brought down to normal and all other manifestations disappeared. (84)

We see, then, that of all the various signs and symptoms which are referable to the eye, exophthalmos is the most common. The presence of exophthalmos is diagnostic providing tumor, arterio-venous, aneurysm, Iright, anatomical disorders, thrombosis of the superior longitudinal sinus, angioneurotic edema, etc. are excluded. On the other hand, the absence of exophthalmos means nothing when hyperthyroidism is suspected. The absence of evident thyroid enlargement and exophthalmos has caused many a competent internist to diagnose and treat patients suffering from the hyperthyroidism of exophthalmic goiter for other conditions. On the other hand, exophthalmos may occasionally be the first symptom noticed.

In the thyrotoxicosis of elderly persons, H. A. Freund and W. B. Cooksey have observed that exophthalmos does not appear. (25)

In general, clinical work the exact analysis of the various eye signs is of little importance. For 
instance, if Graefe's sign is present, the other signs are of little practical interest. However, in doubtful cases each sign must be searched for in turn. 


\section{THE EFFECT OF HYPERTHYROIDISM UPON TIE SKIN}

\section{AND ITS ACCESSORY STRUCTURES}

Upon examination of the skin of a patient suffering from thyrotoxicosis, we find, as a rule, that it is warm, affords a considerable amount of perspiration, and has a soft feeling. This is in contrast to the dry skin seen in hypothyroidism. It is more common than not, to find, in delving into the history that the patient has recently been feeling uncomfortably warm and has a tendency to a flushing of the skin. In fact, he may state that a room temperature which is confortable to him is, as a rule, too cool for the average individual. Besides the increased sense of body heat and a tendency to flushing of the skin, there is a very free perspiration especially of the extremities and the arm pits which the patient will state has not heretofore been present. The flushing is usually particularly present in the face, neck and in some instances the upper chest. The warm, moist skin is relatively constant and when associated with other significant factors is of help in confirming the diagnosis. The hyperidrosis, however, is significant of systemic diseases and likewise is present in thyrotoxicosis. (62) Its presence in the palms of the hands is in contrast to the complaint of the cold, clammy 
hands of the neurastenic. (83)

Hertzler (32-b) considers icterus a rare but significant symptom and in some cases, especially if associated with vomiting, it is a part of the terminal symptom-complex. He refers to a case upon whom he operated and whom he considered an excellent operative risk, which resulted fatally. Jaundice is probably due to cytologic changes in the liver, and may be a sign of impending death. It is usually accompanied by ketonuria. $(23-\mathrm{k})$

Reinhoff (70-e) has said that the pigmentation in hyperthyroidism may be diffuse, approximating true bronzing, but in about 50 per cent of the cases the pigmentation is noticeable only about the eyelids, genitalia, axillae, linea alba and areolae of the breasts. The percentage of cases in which pigmentation is found varies With the observation of different authors; some claim to have observed pigmentation in as high as 70 per cent, others in about 10 per cent, of their respective series. Bram (9-c) quotes Sainton and Fayolle as having seen it in 25 per cent of their series of cases. They describe four principal varieties of this pigrentation.

1. Localized pigmentation

2. More or less diffuse pigmentation

3. Addisonian melanoderma with pigmentation of the mucous membranes 
4. Generalized pigmentation of Addisonian type with discoloration of the mucous membranes In his own series approximately 25 per cent presented Addisonian manifestations in varying degree. He observed that at times the pigmentation consisted of small brown spots somewhat larger than common nevi; in other instances there would occur brown patches extending into the region of the neck. The localized form of pigmentation showed a predilection for the face. Another author reports finding well defined areas of vitiligo or leukoderma on the neck or extremities. (64-d)

Dermographia is almost constantly present and the pilomotor reflexes increase. $(23-k)(64-d)$ It has been found to vary with the severity and duration of Graves' syndrome, being less marked in the early mild form of the disease. Here the tracing will disappear usually within a minute while in the advanced toxemia it may not disappear in ten minutes. $(9-c)$ In the toxic adenomas it will be found to be inconstant and not intense, in contrast to its frequency and high degree of intensity in exophthalmic goiter. (8)

A tophonychia has been observed (83) in many cases. "It consists of symetrical involvement of the fingers, nails in which they may be concave longitudinally and transversely, but more especially there is a recession 
of the matrix so that the matrix terminates anteriorally in a concave instead of a convex line. The recession may be so deep from the tip of the nail that the dirt is removed from under the nail with the greatest difficulty, giving it a very unkept appearance. It is not pronounced in the very early case, but is of great value in diagnosing the late and especially quiescent cases. We have not observed it in any other condition than hyperthyroidism." other conditions of the skin in hyperthyroidism (9-d) are pruritus, urticaria, eczema, psoriasis, seleroderma, petechiae, angioneurotic edema, trophic edema and alopecia.

The urticaria of hyperthyroidism is interesting sinee it seems to be more prone to develop under excitement. They may be focalized in character, as is also true of erythema, or the lesions may more or less generalized. Not too infrequently to attract attention, the hair becomes thin. Itching of the skin is not a common symptom, but if it occurs, it may cause the patient more discomfort than any other symptom. It may be the precursor of an urticaria. Its intensity may vary with the degree of toxicity of the disease, following also the up-and-dom curves of exacerbations and remissions. The pruritus is seldom relieved by scratching. Neither is it aggravated. There may be no visible 
ovidence which would indicate itching.

$$
\text { Probably the most common skin symptom seen }
$$

in hyperthyroid cases is that of the localized blush of the face, neck and chest. In many patients there may be no signs or symptoms whatsoever, related to the skin. 


\section{NIRRVOUSNESS AND TREMOR}

One of the most subjective of all reported symptoms is that of nervousness. It is a vague term, including a number of aspects of nervous instability. It may apply to shakiness of the hands or a state of mental unrest and uneasiness. A patient will frequently complain that she has always been "nervous" but that recently the condition has become more pronounced. Nervousness may be used to mean increased irritability, impatience, apprehansion, intolerance, insomnia or an unusual mental state. In the latter the patient may be optimistic and hopeful of the future or the attitude may be one of marked instability, in which the patient passes frequently from laughter into tears without any apparent adequate cause. Nervousness may be offered as an excuse for selfishness or a number of personality defects. Emotional instability is very frequent and constant. The mental status may be one of unmotivated gaiety, flight of ideas or rapid change of moods. In any event, it exhibits frequent alterations.

The nerrous characteristics of hyperthyroidism are probably more prominent in exophthalmic goiter. The least impetus may be necessary to throw the patient into a wild state of excitement. These patients might be 
compared in all respects to a normal individual who has been subjected to great excitement. There is anxiety, palpitation, tremor, diarrhea and at times poluria.

Extreme irritability is a symptom generally suggested by friends or relatives and life may be made miserable by the patient for other members of the family. They Irequently complain of being neglected. It is obvious that such a situation has at times led to domestic strife and divorce.

The hyperthyroid patient is exceedingly restless, constantly moving and changing positions. He is unable to remain seated very long, but goes and comes, sits and rises, and makes hasty movement, many of which are involuntary and purposeless. He has the desire to accomplish much but his mental instability allows him merely to get started at a task when he suddenly stops. One job after another is frequently tackled, but accomplishment is very small. Many bazaar forms of neuroses or psychoses have been reported accompanying hyperthyroidism and this is especially true of Graves' disease.

Tremor is thought to be, "The reaction of the musculature, pertaining to its toxicity and reactivity, which is derived from the hypersensitivity of the autonomic nerves and their ganglia. The fine tremor of the voluntary muscles is probably comparable to the psyohic instability 
of the central nervous system caused by a toxic agent." (23-k) Although tremor is relatively constant in hyperthyroidism, it is of frequent report in all aysfunctions of the thyroid and other endocrine glands. All authors agree that it is one of the most constant symptoms of thyroid intoxication. The patient seldom complains of tremor, but becomes aware of it only when subjected to the test by the physician.

The sign is best elicited by having the patient stretch out the hands and arms away from the body, with the fingers spread to the maximum degree. In this position tremor is usually visible or palpable by the examiner. The tongue and lower extremities may also be involved. It is usually fine and rapid in quality and the oscillations occur from seven to ten per minute. The eyelids should also be examined for tremor. The neuro-muscular system may produce practically the only signs of hyperthyroidism. A case has been reported of a man age fortyfive with muscular weakness and severe coarse visible tremor of the limbs and entire trunk. The weight loss was ten pounds in eleven months and the appetite good. The basal metabolic readings were plus 37 , plus 29 and plus 18. There was only a questionable thyroid enlargement and the pulse remained usually below 90. There was prompt recovery following partial thyroidectomy. (49) 


\section{THE THYROID CARDIO-VASCUIAR SYSTEM}

Parry (Page 1) in his original article emphasized the importance of the cardiac disturbances associated with disease of the thyroid gland. The first case of this nature which was described by him, (63 A) was that of a married woman, age thirty-seven. Six years before he saw her, she caught cold after childbirth and for a month suffered from acute rheumatic fever. Subsequently, tachycardia and arrythmia developed with two or three nocturnal attacks of dyspnea and hemoptysis. Three months after delivery, while nursing her child, a walnut sized lump appeared on the right side of her neck. This progressively enlarged until Parry saw her, when it had reached an enormous size, occupying both sides of the neck and protruding beyond the jaw. This proved to be thyroid gland enlargement. The patient subsequently developeỏ a general anasarca and died from a cardiac failure.

Among the typical cardiac manifestations of hyperthyroidism are tachycardia, palpitation, auricular fibrillation or flutter, and enlargement. One in eight of all thyroid patients have been recorded as having either dyspnea, palpitation, pain or cough as a chief complaint. (73) The consensus of opinion in the recent 
literature seems to be that the hyperthyroidism, itself, does not have a toxic influence or a direct pathological action on the heart, although, indirectly, it may accelerate the development and progress of pathological lesions which exist from outside influences. (47) Knowing the usual increase in the metabolic processes in the body, the natural physiological result would be for the heart to accelerate. This is the result both of the increased metabolism in the heart and in the body as a whole. (I)

Tachycardia is such a common symptom in hyperthyroidism that all cases howing this symptom to be persistent, should be under suspicion. In mild cases, the heart rate may vary from 90 to 100 per minute while in the more sezere cases, it may be as high as 160 to 180 per minute. In hyperthyroidism, tachycardia and palpitation are present not only during excitement, worry, fear and sudden noises as is true in neurotics, but is also present while the petient is at rest. The degree of tachycardia depends upon the degree of involution in the gland. The rapid pulse may be a residual in the course of involution where the basal metabolic rate has already undergone a really significant depression. In fact, the initially rapid pulse may be the last of all evidences to disappear as the thyroid disease reaches a terminal 
phase of established hyperthyroidism. (73)

The fact, then, that this symptom is constant and persistent, offers considerable aid towards a diagnosis. (15) (73) (83)(64-c) It is only of value in diagnosis if we realize that the pulse rate may be normal in cases of remission. Occasionally a pulse rate which was about 70 preoperatively, will be reduced to perhaps 50 following the disappearance of the hyperthyroidism. (49)

There are those patients whose chief complaint is palpitation. This may come on at any time of the day and occasionally at night. Not infrequently its onset has no relation to exertion, excitement or fright, and may appear when the patient is sitting quietly in a chair. (15) A subjective sensation of throbbing may also be noticeable. It is particularly marked when the head is placed on a pillow at night. Palpitation may be most distressing at times. It should be differentiated from tachycardia in thet the latter may exist wi thout the knowledge of the patient. Palpitation, on the other hand, is a subjective symptom. In other words, the patient becomes aware of his cardiac action and is conseious of his heart pounding in his chest.

Levine (46) considers transient auricular fibrillation as the most characteristic cardiac finding in hyperthyroidism. Auricular flutter has also been seen. 
In these cases, when hyperthyroidism is the etiological factor, the rate fails to respond to digitalis. (46)(82) The one most constant sign of exophthalmic goiter found in the Cleveland Clinic (14-a) was the uniform enlargement of the heart. They explain it as a purely compensating factor for the great increase in the amount of blood which the heart is called upon to transport because of the increased motabolism. Lewis (47) found cardiac hypertrophy in each of twelve cases of hyperthyroidism that came to autopsy. Wilson (81) reported that in twenty-one cases of necropsy cases of exophthalmic goiter and toxic adenomatous goiter, the majority of heart showed some degree of hypertrophy and dilitation. Means and Richardson, (52) on the other hand, found very little dilitation or hypertrophy in twelve cases of exophthalmic goiter upon which they performed autopsies. Cookson (16) made radiographic studies of the size and the shape of the heart in goiter. He remarks that, "The most characteristic picture, yet not perhaps the most frequent when the heart is involved in goiter, shows a slight general enlargement more especially to the left, a high aortic arch, a prominent superior vena cava, and a filling in of the pulmonary bay, so that the whole of the heart's profile on the left from the aortic knob to the apex is more or less straight. As a result 
of these changes, the heart comes to bear a resemblance in shape to that of a ham."

In 1913 Blackford and Sanford (7) made fresh extracts from exophthalmic thyroid and reported it to contain a powerful depressor substance. They found it also to exist in the sera obtained from cases of this disease. They believed it to be present in direct proportion to the acuteness of the disease. Two years later Plummer (69) eliminated the accidental association of a high blood pressure with thyrotoxicosis. 27 per cent of his patients above forty years of age had a systolic blood pressure above 160. A review of the Iiterature up to 1916 showed that Hensen, Gross, Jackson, Bing and Federn considered the systolic pressure in Graves' disease to be high. Gibson, Frankel reported normal findings, while Spiethoff, Donath and others stressed the great variability of the systolic blood pressure in the disease. Taussig (77) found the blood pressure in exophthalmic goiter to simulate that of aortic regurgitation. The blood pressure is high as compared with the diastolic pressure. This author found a variation in the leg and arm systolic pressures, the latter being considerably higher. He believed that identical pressures would aid to exclude the presence of true exophthalmic goiter. Phillips (64-f) also found 
an increased pulse pressure. Yung (83) believes that a pulse rate persistently over 90 with the patient at rest with a systolic pressure of 130 to 150 and a 10 w diastolic pressure of 60 to 40 without a diastolic murmur over the aortic area, combined with a flappy quality of the valve tones and sometimes a systolic murmur at the base transmitted to the left, are very significant of toxic goiter.

In the early and mild cases of hyperthyroidism, there will be no outstanding findings upon physicial examination directed toward the heart. In the advanced cases, however, significant findings may be revealed by inspection, palpation, percussion and auscultation. That $x$-ray studies may be of value has already been suggested.

Since the heart suffering from the overactivity of the thyroid gland is the subject of an abnormal driving mechanism, its beat is apparently more forceful. As a result, the contractions are transmitted with moro or less violence to the anterior chest wall. At times the entire chest may be seen to heave or shake with each beat.

Palpation of the heart oft times reveals the presence of a thrill. This is further evidence of the increased intensity of the apex beat. Since the cardiac 
enlargement is frequently to the left, the apex beat will likewise be felt more laterally than nornal.

The percussion findings are identical with those in any cardiac enlargement.

Auscultation reveals most frequently systolic murmurs, although diastolic murmurs may be present and, if so, are heard with the greatest intensity at the base of the heart. Engelbach's (23-n) remarks concerning the heart are quite generally accepted. "The murmurs may have a distribution beyond the cardiac area, but are rarely transmitted posteriorly to the vertebral region. Their tone quality varies from that of a faint systolic blow to a to-and-fro murmur or an almost continuous hum. They seldom have the clear, high-tone or whistling character of a valvular murmur, but sometimes have a roughened, grating character, which may simulate a pericardial friction rub. The murmurs are distinetly modified by respirations, gradually decreasing in intensity during inspiration, at the end of which the murmur is sometimes entirely absent but begins to increase with the expiration." 


\section{DISORDERS OF THE GASTRO-IITESTINAL TRACT}

In a relatively large number of patients suffering from hyperthyroidism and, in fact, in any disturbance of normal thyroid function, there are associated gastro-intestinal symptoms. Not infrequently these symptoms may be so pronounced that the fundemental disturbance in the thyroid gland is completely obscured. One property possessed by the thyroid gland is that of stimulating secretion, motility ana accelerating body metabolism. Each of these in turn will be manifest by gastro-intestinal symptoms. The overactivity of the thyroid has, then, a striking influence on the gastrointestinal tract. (39) The cause for these symptoms is probably a direct affect of an excess of thyroxin, or of a toxic by-product, upon the autonomic nervous system or upon its visceral nuclei. The acid secretion, enzymes, mucous and disturbance of the peristalsis, motility, atony, and spasticity may all be effected by this process. $(33-1)$

The appetite, as a rule, is increased in contrast to patients with tuberculosis. This increased hunger is probably an effort on the part of nature to obtain additional fuel to feed an increased metabolism. This increased appetitie is probably more apparent in 
the earlier stages of the disease and it presents a strong contrast to the great loss of weight. Phillips $(64-g)$ believes that loss of weight associated with a good appetite is strongly suggestive for the hyperthyroidism of exophthalmic goiter. The cause for excessive appetite in these patients may be the fact that the motility of the stomach is increased considerably and results in an empty feeling in the stomach soon after eating.

In Shirer's (75) series he demonstrated a hypermotility of the stomach in ten out of twelve cases. In another series he showed 92.5 per cent of forty-two cases had it. He noted that hypermotility and anacidity occurred concomitantly in twelve cases of hyperthyroidism. The striking point in his analysis is the apparent change in the gastric motility which follows the clinical control of the hyperthyroidism. There were six cases in which the intestinal motility was increased following operation. 76.12 per cent showed a definite decrease in the motility following operation on the thyroia.

Loss of weight is commonly seen in hyperthyroidism and in some cases may indicate the amount of advancement in the disease. It is seldom, if ever, the only presenting evidence. The loss of ten to thirty or more 
pounds over a period of a few months in spite of a satisfied large appetite may occur. (83) In these cases, of course, diabetes must be excluded from the diagnosis. There are cases, however, which might be classified as border line or atypical in which may be seen very small, variations in the weight. In fact, this may be but a few pounds per year and the patient may notice himself becoming increasingly thin over a period of many months. Here there is rarely any history of sudden and serious weight loss as is so commonly seen in severe hyperthyroidism. The appetite associated with such a case generally remains good and a marked increase is not particularly common. (15)

Nausea is a very common symptom and may be persistent and annoying. It may last for weeks, months or even years. As a rule, it is worse in the morning and more marked after meals, but may have no relation to food whatsoever since it may occur with an empty stomach.

Lockwood (48) in his studies on the digestive tract and endocrine function found diarrhea, nausea and vomiting to occur only in the exophthalmic goiter type or hyperthyroidism and here the percentage was as high as 16. Only 3.3 per cent of his cases had nausea and - vomiting. Hertzler (32-c) found vomiting rarely - 
accompanied by nausea. While Crotti, (17) on the other hand, found that nausea rarely led to vomiting. Hertzler believed it to be a most serious complication. Most of his cases of vomiting with anorexia died within a few days, all those with intermittent vomiting recovered. Both Phillips (64-g) and Crotti (17) report on the common occurrence of gastric flatuleney. They indicate that it is of a most persistent character. These patients attempt to relieve themselves by frequent eructations. The vomiting may take place from four or five times a day to as often as ten to fifteen times a day. It may be watery, slimy or colored with bile, but seldom containing blood. Barker (2) found vomiting and unmotive diarrhea not uncommon in exophthalmic goiter.

Among the most important symptoms of hyperthyroidism which are referable to the digestive tract is diarrhea. It may usher in the aisease, appear at any time during its course, be transient in character, periodic, or even remain permanently when it greatly increases the severity of the disease. In the latter case, the patient may become involuntary. "On the other hand, diarrhea may be of sudden onset, and appear at the crisis of the disease when the tachycardia, ocular, and other manifestations are-most pronounced. This may occur 
in both early and late stages of the disease.

The movements are fluid, bile-tinged, and often contain whole fragments a few hours after same have been eaten, indicating an increased peristalsis of the stomach and intestines in addition to impaired digestion.

The frequent diarrhea may be so prominent and the thyroid signs so obscure that only careful physical study and pharmacodynamic tests enable the clinician to demonstrate that the diarrhea is dependent upon hyperactivity of the thyroid.

Again the diarrhea takes the type known as nocturnal diarrhea, characterized by a number of passages of the bowel rapidiy following one another in the early morning. These patients often have a ravenous appetite, eat much more than they can digest, and later develop true enterocolitis with mucous in the stools." (39) McCullagh (49) remarks that in his clinic diarrhea has been seen much less frequently in the last six to eight years than it was previous to that time. He has never seen a case of hyperthyroidism in his study in which the gastro-intestinal symptoms were the only clinical evidence of the disease. 4.4 per cent of Lockwood's cases had diarrhea. (48) This symptom may occur intermittently three or four times a year. I have recentiy 
seen a patient in which this has occurred for the last two years. Bach time the patient believed himself to have an attack of "intestinal flu". He lost twenty pounds of weight in the last four months. The last attack of diarrhea followed a severe cold and persisted following the cold until the patient was seen by his Doctor. During the intervening months since the onset of the diarrhea, he has developed an extreme nervousness and tremor. The first basal metabolie reading was plus 82 . The second dropped to plus 50 the following day.

Constipation has occurred frequently enough in Graves' disease to lead some authors to assume a relationship betmeen the constipation and the goiter. (32-c) This may be present even at the increased metabolic levels of hyperfunction. (73)

For some time it has been recognized that achlorhydria frequently accompanies hyperthyroidism. of seven hundred and forty-five gastric analyses examined by a British investigator on cases taken at random 22.5 per cent showed achlorhydria. In twenty-one of these cases which had Graves' disease, 76 per cent showed achlorhydria and 90 per cent a marked reduction or absence of hydorchloric acid. (56) Lockwood's series (48) showed 41.6 per cent achlorhydria while Wolpe (82 A) 
found achylia constant in all cases of the pronounced types of exophthalmic golter, but the hydrochloric acid unchanged in other types of hyperthyroidism. Similar results have been found by holl and scott, (55) Brown, (11) Barker, (2) Berryhill and Williams, (6) Lerman and Heans, (45) King, (39) and Leist. (44) It has been suggested by Brown that a larger percentage of achlorhydria is found in cases of short duration, one year or less, than when the disease has been present for a longer period of time. Lerman and Means found the percentage higher in males than in females by 19 per cent. The majority of these patients remain achlorhydric after the administration of histamine. The incidence has been reported to be about the same in Graves' disease and in toxic adenoma. In one series of forty-two cases, thirty-one showed nomal gastric acidity six months after thyroidectomy. Forty-nine of the series of one hundred and fifty-ifve hyperthyroid cases which I have examined have been subjected to gastric analysis, Eleven of these cases showed no free hydrochloric acid. This represented five toxic nodular goiters, two toxic diffuse goiters, two non-toxic goiters and two unclassified cases. The normal free hydrochloric acid is generally - considered to be from 20 to 40 degrees, while the normal 
for the total acidity is from 40 to 60 degrees. Fourteen of this series were definitely $10 \mathrm{w}$ in acidity, there being five below 10 degrees and nine between 10 and 20 degrees. If we consider 40 degrees as the upper limit of normal, then elght cases would represent hyperacidity. Fourteen cases fall within the normal Iimit.

The average total acidity of these cases was 46.5 degrees which is within the normal range. Twenty of these cases, or 40 per cent, however, were low in total acidity. 
THE IUUSCULAR STSTEM IN FYPERTIYYROIDISM

Excessive fatigue is a common complaint in mild hyperthyroidism. Patients complain of great weakness and extreme exhaustion frequently following severe or prolonged effort. The desire and eagerness to perform work is usually present, but the patient having worked but a short time becomes so inordinately tired that he fails to carry it to its conclusion. Not infrequently the story is received that the knees "give way". There may be at times muscular cramps of the extremities. The evidence of myesthenia especially in the quadriceps muscles was called to attention by Plummer (68) in 1916. He described a test for this quadriceps weakness which was as follows: the patient is instructed to mount upon a chair but while doing so not to touch the chair or any part of the body with the hands. The result is rated simply negative or positive depending upon the patient's ability or inability to get upon the chair. He found that most cases of exophthalmic goiter, with any degree of severity, beyond the mildest, are unable to perform this task without the aid of the hands. Jackson (35-a) considered this test one of the four most important diagnostic signs of this disease and considered it also of great prognostie importance from a surgical 
standpoint. He uses it frequently in differentiating patients with true exophthalmic goiter from those with neurasthenia in whom hyperthyroidism is suspected, due to the presence of rapid pulse and nervousness. The neurasinenic either performs the test with no sign of quadriceps weakness or he hesitates so long that there is an appreciable wasting of muscular energy in his effort. Attention is called to the fact that patients of short stature, tested by Plummer's technique for quadriceps weakness, are apt to be mistakenly judged as having hyperthyroidism, unless a suitably low chair or table be employed in the test. The chair should be in proportion to the stature of the patient. (50)

This test is given considerable value in diagnosis by Clue and Adams, (15) Engelbach $(23-\mathrm{m})$ and Yung. (83) In the history a clue may be found by inquiring into the ability of the patient to climb stairs. 


\section{GENITO-URINARY DISTURBANCES}

There are no gross changes in the organs of the genito-urinary system which are of any great significance. Hyperthyroidism should be considered in any case in which a persistent or alimentary glycosuria exists. Creatinuria is said to exist in cases of hyperthyroidism. (63-a) Similarly an increase in the urea, total nitrogen, uric acid and phosphates has also been suggested. $(70-f)$

The excessive thyroxin supply has a striking effect upon gonadal function. In contrast to the effect present in hypothyroidism, the activity of the gonads is suppressed. Iikewise, the menses diminish in amount and duration, frequently becoming irregular or ceasing entirely. $(23-m)(15)(70-f)$ This is apparently the general consensus of opinion although there are those who believe that the interval may be both longer and shorter in the same individual and the flow at times scanty and at others profuse. (73) The latter opinion applies more to thyroid disease in general than it does to hyperthyroidism. In one hunared cases of acuto fulminating hyperthyroidism with exophthalmos ' in' women between the years of sixteen and thirty which have been - reported, irregularity in the appearanee and duration of 
the menstrual period was the first indication of the disease. Here this irregularity preceded the onset of. any other signs and symptoms of hyperthyroidism by an average of six months. In most cases, when the disease was at its height, menstruation was completely suppressed, and returned again usually four months after thyroidec tomy. $(70-f)$ 


\section{THE BLOOD PICTURE IN HYPERTHYROIDISMI}

There has been a definite increase in the interest shown in the study of the blood picture which accompanies this disease, especially in the last few years. The major investigators have done their work on exophthalmic goiter. In 1908 Kocher (40-a) pointed out that the differential formula in cases, which patients were suffering from exophthalmic goiter, might be abnormal showing a preponderance of lymphocytic elements. He thought that this relative lymphocytosis represented an index of the severity of the disease. In 1918 plummer (67) reported on five hundred and seventy-eight cases of exophthalmic goiter studied at the Nayo Clinic in 1912 and 1913. He found a relative and absolute mononeucleosis and a percentage decrease in the polymorphonucleur neutrophiles. There was no increase in eosinophiles, and anemia was not characteristic of the disease. He concluded, therefore, that the differential blood count was only of limited value in the diagnosis of the disease. In general, there is a Ieucopenia of from 3500 to 6000 (31) (32-d)(28) and this is usually at the expense of the polynuclear leucocytes. This is especially true and most marked in cases which have undergone great weight losses. This 
leucopenia was observed in 1908 by Kocher. (40-b) Neutropenia and Iymphocytosis was observed in the same report. The leucopenia has been considered of such importance in the diagnosis of this disease that when it is accompanied by a relative lymphocytosis it has been considered as pathognomic of Graves' disease. (9-e) It is not infrequent to find a 50 per cent decrease in the polymorphoneutrophiles. The white blood count may be considered as indicative of the course and prognosis in exophthalmic goiter. A high lymphocyte count with a moderate leucopenia is more favorable than a marked leucopenia with a low lymphocyte count. $(9-e)$ There are differences of opinion as to the presence or absence of an anemia. The preponderance of opinion seems to be that there is little or no change in the number of red blood cells or hemoglobin. (67) (40) (36) (3) Those investigators of contrasting opinion are just as insistent that an anemia is characteristic but are willing to admit, as a rule, that it is secondary in nature. Their argument is that the red. count is normal in early cases but as the disease progresses they may become reduced to $4,000,000$ or less, with a greater diminution of hemoglobin. $(9-e)(35-d)$

A slight tendency to macrocytosis has been noted in some instances. (40) 
Gottliebe (40) found that, "Kocher's blood picture was present in practically all cases of hyperthyroidism. In addition as a striking observation an increase in the segmentation of the neutrophiles was noted, a shift to the right. Although the shift to the right may not be specific for a thyroid disturbance, just as Kocher's blood picture is not specific, it must be considered as a considerable aid in the diagnosis, since it is not irequently observed in other pathologic conditions.

The whole blood picture is that of a definitely depressed myeloid system. The Iymphocytosis though mostly relative is also absolute."

Both a relative momocytosis and a relative lymphocytosis have been considered as the most characteristic finding in hyperthyroidism. In the series studied by Herz and Lerman, (31) the former was considered most outstanding. They did find a relative lymphocytosis but deny that the absolute number of lymphocytes is increased. The variation in the differential was correlated by these authors with the basal metabolic rate. The correlation was direct with the percentage of monocytes and polymorphonuclears and inverse with the percentage of Iymphocytes. There was no relationship between the level of metabolism and 
the total lymphocyte count.

The lymphocytes, probably more than any other of the leucocytes, are susceptible to variations in the endocrine system. (34)(73) With fer exceptions, a definite lymphocytosis throughout the thyroid group of dysfunctions is agreed upon. There is, however, conjecture as to the significance of an eosinophilia. Hoskins and sleeper (34) believe that it points towards pituitary rather than thyroid deficiency. Rowe (73) believes there is a tendency to eosinophilia in the dysfunctional group, but admits that it is scarcely significant. Relative lymphocytosis was observed in 67 per cent in the cases of hyperthyroidism studied by Menkin. (53) It was more frequently seen in patients who had exophthalmos superimposed upon the usual clinical signs of hyperthyroidism.

\section{RELATIONSHIP OF EXOPHTIALMOS}

TO INIPHOCYTE COUNT

$$
\begin{gathered}
\text { Hyperthyroidism } \\
\text { Without } \\
\text { Exophthalmos }
\end{gathered}
$$

Total cases

Number of relative

lymphocytes in per cent
44

50
Hyperthyroidism with Ixophthalmos

56 80 
He states that, "In patients with exophthalmos, thyroidectomy decreases the relative lymphocytosis and restores a normal differential formula. It is suggested that the relative Iymphocytosis in cases of exophthalmic goiter is due to sympathetic stimulation of lymphoid structure, particularly of the spleen, which causes it to contract. Some patients with hyperthyroidism but without signs of exophthalmos show a relative lymphocytosis apparently not relieved by thyroidectomy." Crile and Phillips (64-d) are among the school who consider the most characteristic change in the blood picture in hyperthyroidism as a moderate degree of lymphocytosis. Probably the most comprehensive study of the blood picture in exophthalmic goiter is that by Jackson who reported a study of 600 cases in 1931. (36) In this series, blood studies were made on the following types of goiter: colloid goiter, one hundred cases; nontoxic adenoma, one hundred cases; toxic adenoma, two hundred cases; exophthalmic goiter, two hundred cases. The average blood count for this entire group is shown in Table I, Page 67. This study would indicate that a leucopenia does not occur in hyperthyroidism. Neither, also does an anemia occur characteristically. His studies are not in accord with those 


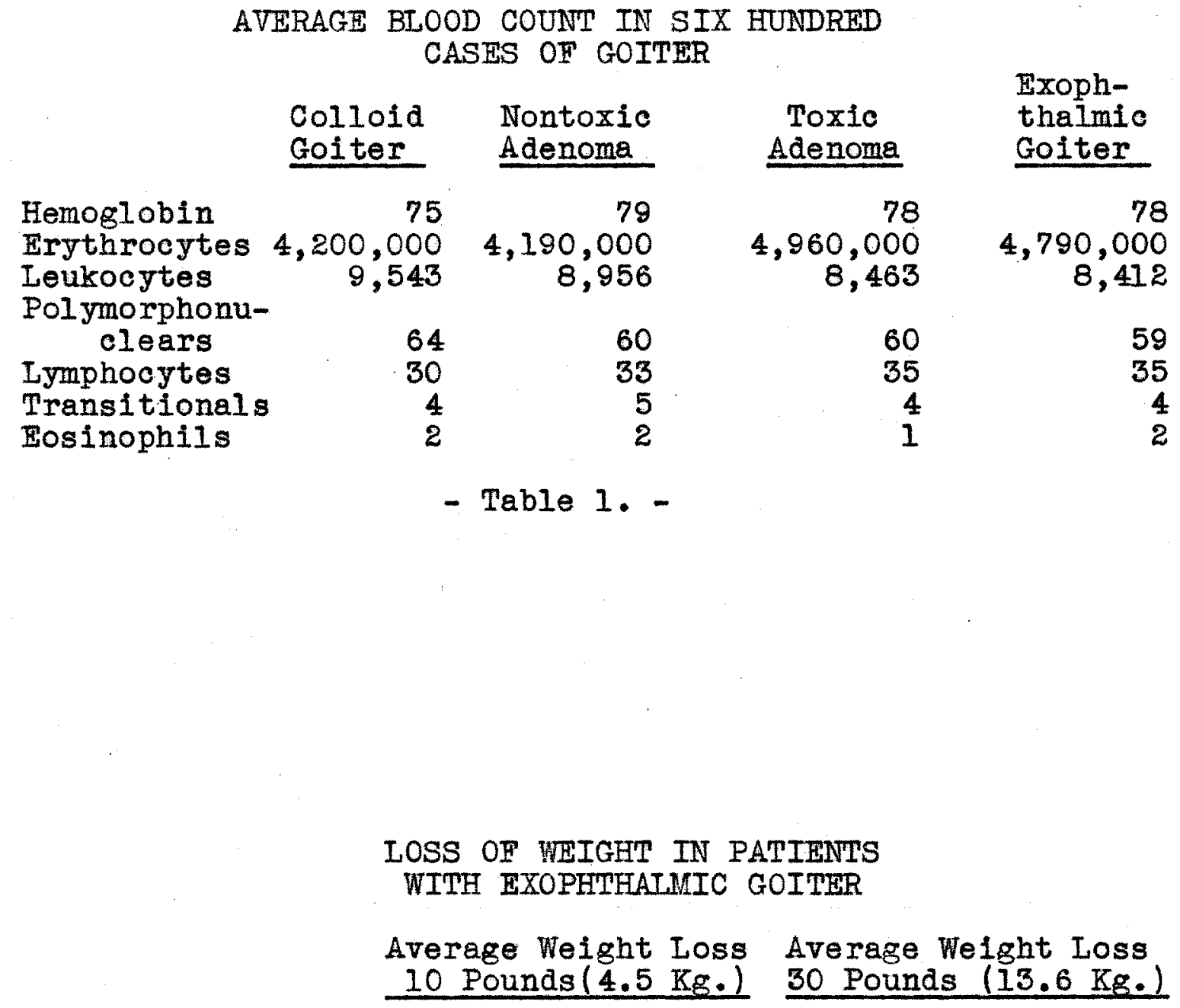

Exophthalmic Goiter

Leukocytes

Polymorphonuclears

Lymphocytes $\begin{array}{rr}7,261 & 8,089 \\ 62 & 65 \\ 33 & 31\end{array}$

- Table 2. - 
previously mentioned of Herz and Lerman in that they indicated that the blood count does not vary according to the metabolic rate. The lymphocytes are not increased when the rate is elevated, or decreased when it is lowered. This is indicated by the cases which I have studied, since some cases with the highest basal metabolic rate have the Iow Iymphocyte counts. one case,for example, had a basal rate of plus 88 and a lymphocyte count of 24 .

One might reason that since the amount of Weight loss indicates the severity of the disease, that those patients with the greatest weight loss might show the highest lymphocyte count. However, Jackson's table, as shown on Page 67, refutes this statement. He concludes, therefore, that the blood picture in hyperthyroidism does not vary essentially from that of a nornal person, and that the differential blood count in this disease is neither or diagnostic or prognostic significance. Although he found that following thyroiaectomy the polymorphonuclear count increased and the Iymphocyte count decreased, he does not believe that the blood picture is of any practical clinical importance. These studies would indicate the contrast of the blood picture in hyperthyroidism with that of myxedema which show:- a reduced hemoglobin and a normal white blood count. (22) 
In the series which I have investigated, the average polymorphonuclear count was 61 per cent of which 60 per cent were segmented forms. This represents one hundred and twenty-three cases. The highest staph form noted was 24 per cent and in this case, there were 70 per cent polys, 18 per cent lymphocytes, 8 per cent monocytes and one eosinophile. Staph forms were seen in sixty-eight cases of the one hundred and twenty-three. In these sixty-eight cases the average staph count was 7.5 per cent. The highest segmented poly count was 87 per cent and the lowest 25 per cent. The variation in the differential count in the toxio nodular form and the toxic diffuse form of goiter has not yet been investigated in these cases.

The Iymphocyte count varied from 62 per cent to 7 per cent. The average was 33.3 per cent, a definite lymphocytosis. I could not find that the eosinophiles or monocytes varied from the normal. 
THE VALUT OF BASAI METABOLIC RATE IN DIAGNOSIS

For a number of years the average physician being confronted with a suggestive case of thyrotoxicosis has had as his first thought the basal metabolic rate. In Iact, it has come to be relied upon to such an extent that when a normal basal report is returned from the laboratory such a diagnosis is dismissed from consideration. This is the attitude that Levine (46) has taken in his studies. However, to make the metabolic test the sole measure of determination for the presence or absence of thyrotoxicosis is unfair to the patient since many men have found this measure to be unreliable in certain atypical cases.

A conservative attitude on the subject will probably be of considerable aid to the physician when he is confronted with boräerline or atypical cases. It is true that the basal metabolic rate measurements supply an additional method of precision which is of great value. In those cases where all the classical symptoms are present, a basal metabolic determination is probably superiluous to the diagnosis, especially in the case of the trained internist. On the other hand, when some or most of these clinical signs and symptoms are lacking or insufficient to warrant a 
definite diagnosis, repeated basal metabolism measurements are of inestimable value in the establishment of an accurate diagnosis. Rowe (73) is apparently among those who would rely almost entirely upon the basal rate in his diagnoses. He has found values above plus 100 per cent with a relative frequency in the literature. In his clinic a plus 87 was the maximum and the average was plus 32. (74) Reinhoff (70-g) remarks, "Plevation of the basal metabolic rate, which is always present in cases of hyperthyroidism, except during remission, is a most reliable test." Jackson (35-e) has the same opinion, believing that establishment of a nomal basal metabolic rate in neurotic young women with symptoms of hyperthyroidism as well as symmetrical enlargement of the thyroid gland, eliminates the possibility of hyperthyroidism and surgery.

"It seems certain," says Christie (14-a) "that an increase in basal metabolism represents the fundamental and basic symptoms of exophthalmic goiter, just as hyperglycemia represents the basic symptom of diabetes mellitus. There is no other condition in which such an increase in metabolism persists seven days out of the week and thirty days out of the month, as is the case in exophthalmic goiter. All of the signs and symptoms of the disease are accentuated-in proportion 
to the increase in metebolism and subsides as the netabolism again approaches the normal." It is quite generally acceted that the basal measurement is an index of the severity of the thyrotoxicosis.

Vithin the last ten years meny cases with normal or subnormal rates have come to the foreground. The lowest basal metabolic rate in the initial test for hyperthyroidism that has been encountered in the literature studied was that of a case reported by Morris. (58) The patient had a basal rate of minus 32 prior to operation and one year after operation a plus 12 with relief of toxic symptoms without further treatment. Nervous phenomena and progressive exophthalmos were manifested, in a case reported by Haines, (30) but the basal metabolis rate was minus 14. Then iodine was given the rate dropped to minus 28 and the symptoms disappeared. No one would deny that the mejority of cases of hyperthyroidism of clinioal importance have an associeted elevated basal metabolic rate. on the other hand, however, a metabolic determination is not ordinarly ordered unless a disease of endocrine or metabolic nature is suspected. It, therefore, renains important to bear in mind the type of cases in which it is easy to be misled. In the questionable cases, then, the prudent diagnosticisn will be prepared to depend entirely upon clinical evidence. Morris (58) believes that the 
metabolic rate should be entirely disregarded when there is clinical evidence of throtoxicosis and a demonstrable goiter. Although helpful when elevated, it is a sign which should be ignored, when normal or subnormal, in the presence of unmistakable evidence of thyrotoxic symptoms and signs. This is especially true in the presence of heart disease, in which case operative treatment is indicated regardless of the basal metabolic rate.

Too frequently patients are referred for basal metabolic rates only, the physician deeming that rate alone sufficient to make a diagnosis. High readings may be obtained through errors of technic, oxygen leakage about the mask or tank; or an increased rate due to a preceeding restless night, fear and the unaccustomedness of the patient to the test. In many cases several tests are necessary. The patient should always be hospitalized and it is well that he should spend the previous night there. It is not unusual to have the first reading of plus 25, next plus 15 then plus 10 and at last plus 5 or zero. Obviously in such a case it is usually possible to eliminate toxic goiter. If the rate is presistently high, Lugol's solution may be administered as a diagnostic measure. If after a week or two the pulse rate and the metabolic rate are 
reduced, the conelusion may be made that the case is one of toxic goiter.

Engelbach $(23-h)$ made a comparison of the basal metabolisms of the ocular and non-ocular exophthalmic goiters with those other rorms of hyperthyroidisms. He indicates as a result that the high basal metabolic rates are more likely to prevail in those having exophthalmos. There is a much lower degree of hypermetabolism in the non-goiterous hyperthyroidisms, than in cases of exophthalmic goiter. Only six out of ninty-five cases of non-goiterous hyperthyroidism had basal metabolic rates above plus 51 while nineteen out of fifty-two cases of exophthalmic goiter had basal metabolic rates above plus 5l. His comparison demonstrates that the intensity of the intoxication is about the same in both ocular and non-ocular forms of exophthalmic goiter. The index figure is apt to be very irregular in Graves' disease while showing a steadier tendency to rise in toxic adenoma. (2l-b)

"The average metabolic rate in adenoma with hyperthyroidism, as determined at the Jackson Clinic, is plus 38 per cent. The maximal rate observed has been plus 65 per cent. It is evident from these figures that the average rate is considerably lower than in exophthalmic goiter, -in which conaition it is not very 
extraordinary for the rate to go as high as plus 100 per cent. The rate in adenomatous goiter does not have the same significance as in exophthalmic goiter. In adenoma with hyperthyroidism there is a serious and permanent damage to the cardio-renal-vascular system, which, of course, is not registered by the metabolic rate. Frequently a patient wlll be observed in a serious condition while the rate is below plus 30 per cent. The rate in patients with adenomatous goiters is chiefly of value in alding the diagnostician to determine whether or not symptoms of hyperthyroidism are developing." (35-f)

The figures in our series parallel these quite strikingly, with the exception of the fact that we did not note the great variation between the average basal metabolic rate in toxic nodular goiter was 32 per cent, while in exophthalmic goiter it was plus 47 per cent. The maximum rate observed in this serles was plus 96 per cent, which occurred in exophthalmic goiter. The highest rate in toxic nodular goiter was plus 74 per cent. The low in the former was plus 1 per cent and plus 2 per cent in the latter. 


\section{IISCELIANEOUS IRSTS AND LABORATORY FINDINGS IN HYP ERTHYROIDISM}

\section{The Serum Test for Hyperthyroidism}

Kottmann originally devised this test in Switzerland. (42) D'Houbler, (18) and Bram $(9-1)$ have found it fairly reliable as an index to thyroid function. The Crile Clinic has tested fifty-eight clearly defined cases of exophthalmic goiter, fifty-seven of which showed positive results by this method. (18) The technic for this test may be found in any of the above references.

The Adrenalin Sensitization Test

This test, sometimes called the Goetsch Test, Was described by that author in 1918. (27) It is based on the fact that an increased amount of thyroid secretion produces, by virtue of the sensitizing action of thyroid secretion upon the sympathetic nerves, a condition of hypersensitiveness to adrenalin. The technic for this test requires the patient to be at rest for two days previous. Record is made of the blood pressure, pulse and respirations and general condition of the patient for two or three examinations prior to the beginning of the test. Then 7 minims of adrenalin chloride, 1:1000 are injected subcutaneously into the deltoid region. 
Following this the blood pressure, pulse rate and respiratory rate are taken every two and one-half minutes for ten minutes, then every five minutes for one hour and then every ten minutes for one-half hour. Goetsch found the test of greatest value in the diagnosis of a large group of borderline cases, resembling in some respects true hyperthyroidism, but without definite recognizable symptoms. Besides the above observations the examiner should note nervousness, tremor of the fingers, hyperidriosis, size of the pupil, pallor or flushing of the skin and any other untoward signs or symptoms. Dinsmore (19) found 89 per cent of two hundred and thirteen cases of hyperthyroid showed positive reactions by this method. The Complement Fixation Test

In 1920 Berkeley and Koopman described a serum ifration test for diagnosis of hyperthyroidism. They found that the blood of some patients with Graves' disease would bind complement in the presence of an antigen made from normal glands. (4) (5) (41) In 1931, however, Novick (61) presented evidence indicating that no increase of complement value or significant deviation from the normal range was present. His series constituted thirty-one unclassified cases of hyperthyroiaism. 
The Intradermal Salt Solution Test

This test was described in 1929 and detects changes in the avidity of tissue for water. Normally the elevated areas produced by the intradermal injection of salt solution become impalpable only after fifty to one hundred minutes or longer. In hyperthyroidism a more rapid disappearance occurs. The rate of disappearance seems to be inversely proportional to the severity of the condition, and hence may be of considerable prognostic value. Its diagnostic value may be limited since the same reaction occurs in all types of toxemia, including infections and the toxemias of pregnaney, circulatory insufficiency and dehydration. (57)

Quinine Diagnostic Test

This test was devised by Bram (10) and consists in dispensing to the patient a dozen capsules each containing 10 grains of quinine sulphate. The patient takes one capsule four times a day. Patients in whom the thyroid function is nomal or below nomal will develop cinchonism by the time 20 to 30 grains have been taken. Persons with hyperthyroidism may take 30 grains a day for months with no signs of toxicity from the drug. This test is useful in the confirmation of hyperthyroidism associated with either adenomatous goiter or exophthalmic goiter, but the percentage or error is considerably less 
in the latter. The exophthalmic goiter series of Bram revealed 95.6 per cent positives.

$X$-ray is of value in determining the presence of goiter in cases showing toxic symptoms. The movement of the goiter shadow with deep inspiration and expiration and during the act of swallowing is almost pathognomic of thyroid enlargement. Careful radiographic examinations should be made in all cases with the clinical symptoms of hyperthyroidism and a history which would suggest intrathoracic goiter. (60)

A low blood cholesterol is the rule in hyperthyroidism. (63-b) Hyperglycemia is present in some cases of the disease. (63-c) A low surface tension of the plasma is present in hyperthyroidism, but it is not of diagnostic interest since it may also be low in nephrosis, nephritis, uremia, jaundice and severe anemias. (59) In some cases a low serum protein is apparently closely associated with long standing hyperthyroidism. (49) The dextrose tolerance curve is usually high and resembles that in diabetes. (37) 


\section{SUMRALRY}

We see, then, that there are two main types of hyperthyroidism, that which eminates from exophthalmic goiter and that from adenoma of the thyroid. There are symptoms and signs characteristic of each, but, in general, there is no spectacular difference. As a result, from a diagnostic standpoint, hyperthyroidism is a clinical entity. From a standpoint of therapy, there may be advantages in differentiating the two. The diagnosis of hyperthyroidism rests upon the complaints of the patient, clinical evidence and laboratory findings. Nl may be of value, but each has its limitations. Hyperthyroidism may develop at any age and mey occur in both male and female, although the preponderance is in favor of the latter. If the patient presents an enlarged thyroid gland and any symptoms of toxicity whatsoever, he certainly deserves all of the clinical and laboratory tests available until a positive diagnosis is made. If there is no enlargement, we must remember the many cases which have been reported in which no such finding was present.

The basal metabolic rate is at present the most accurate and most widely accepted confirmatory evidence of the presence of the disease. - The fact that 
hyperthyroidism may exist in the face of a low metabolic rate should place every clinician on his guard especially if there are sufficient signs and symptoms present to suggest the diagnosis. The cutaneous, nervous, cardiovascular and gastro-intestinal symptoms must all be considered. In the advanced cases, these alone will many times make the diagnosis. In the mild cases, however, extremely close observation is necessery. As far as the blood picture is concerned, it is at present of very Iimited value. It is true that the preponderance of evidence points to a relative lymphocytosis, but this would hardly carry sufficient welght to add very heavily towards a diagnosis. The Kottmann serum test is evidently of considerable value, but is not yet in universal use. The quinine diagnostic test is still relatively new. More investigetions will probably determine its actual value.

In most cases of exophthalmic goiter, an increasea metabolic rate, a symmetrical, diffuse enlargement of the thyroid and the clinical manifestations of exophthalmos will usually make the diagnosis. In any case of hyperthyroidism, a careful survey of the symptoms, signs and laboratory data along with the special diagnostic tests, will seldom fail to lead to the correct diagnosis. 


\section{BIBLIOGRAPHY}

1. Andrus, E.C. and McEechern, D.: The Cardiac Manifestations of Hyperthyroidism, Am. J. Med. Sci. 183: 741,1932 .

1A. Ashoff, quoted by Ingelbach, 70-c.

2. Barker, L.. .: Gastro-Intestinal symptoms in Exophthalmic Goiter, Tr. Am. Gastr. Znterol. Ass'n. Misy 7, 1918.

3. Bena, J.: The Relation of mhyroid Disease to Blood Disorders, Thesis, Uni. or Nebr. Hed. College p. 28, 1936 .

4. Berkeley, W.N.: Diaghosis of Poxic Thyroid statos by A Serum Fixation Test, Med. Rec.101:139, 1922.

5. Berkeley, W.N. and Koopmann, J.: Preliminary Report on a New Method for the clinical Diagnosis of Toxic Thyroid States, Med. Rec. 97:1035, 1920.

6. BerryhilI, 票.R. and Villiams, H.A.: A Study of the Gestric Secretion in Hyperthyroidism Before and After Operation, J. Clin. Invest., 11:753, 1932.

7. Blackford, J.M. and Sanford, A.H.: A Demonstration of a Depressor Substance in the serum of the Blood of Patients Affected with Fxophthalmic Goiter, am. J. Med. Sci., 146:797, 1913.

7A. Boothby, quoted by Ingelbach, 23-f.

8. Bram, I.: Progress in the study and Treatment of Goiter, clin. Hed. and Surg., 37:11, 1930.

9. Bram, I.: Goiter: Nonsurgical Types and Treatment, N.Y. Macmilian, 1924. (a) p.109, (b) chap.13, (c) $\mathrm{p} .196$, (d) p.198, (e) p.16I, (f) p.244.

10. Bram, I.: Tolerance for uinine in Bxophthalmic Goiter, Arch. Int. Med., 42.53, 1928.

11. Brown, Alfred: The Influence of Hyperthyroidism Upon the Secretion of Free Hydrochloric Acid, Ann. Surg., 91:324, 1930. 
12. Cecil, R.I.: A Textbook of Nedicine, Phila. Saunders, 1934, $\mathrm{p}$.

13. Chercot snd Basedow, quoted from Reinhoff, 70-a.

14. Chrietie, D.D.: The Thyroid Gland, Crile, G. W. and associates, Phila. Saunders, 1922. (a) p.1501.

15. Clute, H.M. and Adams, H.D.: The Diagnosis of Borderline Hyperthyroldism, New ing. J. Med. Juns 12, 1930.

16. Cookson, H.: The Size and Shape of the Heart in Goiter, Proc. Roy. Soc. Med., 25:1517, 1952.

17. Crotti, A.: Thyroid and Thymus, Phila. Lea and Febiger, 1922, p.380.

18. DHHoubler, F.: The Thyroid Gland: Crile, G. W, and associates, 1922, Phila. Seunders, p. 105.

19. Dinsmore, R.S.: The Thyroid Gland: Crile, G.H. and associated, Phila. Saunders, p.100.

20. Dorland, 获.A.: Medical Dictionary, Phila. Saunders 1932.

21. Eason, John: Exophthalmic Golter, N.Y., Macmillan, 1927. (a) p.83, (b) p.103.

22. Emery, E.A.: The Blood in Myxedeme, Mm. J. Med. Sci., 165:582, 1923.

23. Engelbach, 郦: : Endocrine Medicine, Belto. Md., C.C.Thamas, 1932., (a) p.400, (b) p.360, (c) p.386, (a) P.299, (e) p.361, (f) p.398, (8) p.411, (h) $\mathrm{p} .395$, (i) p.410, (j) p.376, (k) p.584, (I) $\mathrm{p} .382$, (m) $\mathrm{p} .397$, (n) $\mathrm{p} .367$

24. Fernandez-Sanz, E.: Anales de la real. Acad de Med Hedrid, Hay 1917. Quoted from Bram (9-a)

25. Fround, H.A. and cooksey, 留.B.: Thyrotoxicosis in Flderly Persons 1 thout Signs of Goiter, J.A.M.A. $94: 1891,1930$.

26. Gley, E.: The Internal Secretions, N.Y., Pqul B. Hoeber, 1917, p.216. 
27. Goetsch, F.: Newer Methods in the Diagnosis of Thyroid Disoraers: pathological and clinical, N.Y. State Med. J., 18:259, 1918.

28. Gottleibe, R.: Blood studies in Hyperthyroidism, J. Lab and Clin. Med., 19:371, 1934.

29. Graves, R.J.: Clinicel Leetures, London Med, and Surg. J., $7:$ pt.2:516-517, 1835 .

30. Haines, S.F.: Exophthalmic Goiter and Myxedema, Endocrimology, 12:55, 1928 ,

31. Hertz, S. and Lerman, J.: The Blood Pioture in Exophthalmic Goiter and its Changes Resulting from Iodine and Operation., J. CIin. Invest. $11: 1179,1923$.

32. Hertzlex, A.T.: Diseases of the Thyroid Gland, St. Louis, Mosby, 1929., (a) p.18, (b) p.146, (c) $\mathrm{p} .135$, (d) $\mathrm{p} .138$.

35. Horseley, V.: The Pathology of the Thyroid Gland, abstract of the Bromn Lectures delivered at Uni. of Lond., Lancet, Lond. 2:1163-1169, 1886.

34. Hoskins, R.G. and Sleeper, F.H.: Case Report, Indocrimology, 13:469, 1929 .

35. Jackson, L.S.: Goiter and Other Diseases of the Thyroid GIand, N.Y., P.B. Hoober, I926.,

(a) p.101, (b) pp.55 and 58, (c) p.96, (a) p.104, (e) p.206, (f) pp.207 and 208 .

36. Jeckson, A.S.: The Blood Pioture in Six Hundred Cases of Exophthalmic Goiter, J.A.M.A. $97: 1954,1931$.

37. John, H.J.: Hyperthyroidism Shoming Carbohydrate Metabolism Disturbances: Ten Years Study and Following Up of cases, J.A.M.A., 99:620-627, 1932.

38. Joll, C.A.: Diseases of the Thyrold Gland, Lond. Heinemann, 1932.

39. King, L.H.: Gestro-Intestinal in Metabolic Diseases and in Diseases of the Ductless Glands., Med. Clin., No. Am., 2:1660, 1919. 
40. Kocher, T.: Blutuntersuchungen bei Morbus Basedowi, Aroh. f. Klin. Chir., 87:131, 1908. (a) quoted by Menkin, 53, (b) quoted by Gottleibe, 28.

41. Koopmann, I.: Technique of Complement Fixation Reaction in Basedow's Disease, Proc. N.Y. Path. Soc., 21:56, 1921.

42. Kottmann, Karl, S.: Med. Wochensch. 1:644, 1920 Guoted from D'Houbler, 18.

43. Lahey, F.H.: Non-Activiated (Apathetic) type of Hyperthyroidism, Hew Eng. J. Med, 204:747-748, 1931.

44. Leist, M.: Wien. Arch. 1 . inn. Med. 2:491, June 30, 1931, 隹str. J.A.M.A. 77:242, 1921

45. Lerman, J. and Heans, J.H.: The Gastric Secretion in Exophthalmic Goiter and Nyxedema. J.Clin. Invest. 11:167, 1932.

46. Levine, S.A.: Unrecognized Hyperthyroidism Masked as Heart Disease. Ann. Int. Med., 4:67, 1930.

47. Lewis, W.: Hyperthyroidism and Associated Pathology., Am. J. Hed. Soi., 181:65, 1931.

48. Lockwood, B.C.: The Digestive Tract and Endocrine Function, J.A.M.A., 85:1033, 1925.

48A. Lowi, O. and Wayer, H.: Ueber die wirkung synthetischer dem Adrenalin verwandter stoffe, Arch. 1 exper. path. u. phamokol, Leipz 53:213-236, 1905. quoted by Reinhoff, 70-d.

49. Mccullagh, 瑟.P.: Atypical Hyperthyroidism, Med. Clin. N. Am., 19:1733, 1936.

50. Marcus, I.H.: Metabolism in Exophthalmic GoiterShort stature of Patient-Cause of Frrow in Performing Plummer's Test Por Quadriceps Woakness. Bndocrimology. 20:108, 1936.

51. Marine, D.: Cowdry's Special Cytology, Vol.2, N.Y., Hoeber, 1932, p. 799.

52. Means, J.H. and Richardson, E.P.: Diserses or the Thyroid Gland, Oxford Monographs, Vol.4, ox. Uni. Press, 1929. 
53. Menkin, $V_{\text {.: }}$ Relative Lymphocytosis in Fyperthyroidism., Arch. Int. Med., 42:419, 1928.

54. Mobius, P.J.: Ueber Insufficiency der Convergenz bel Morbus Basedow, Centralb. P. Narvenh., Leip. 9:356-358, 1886, quoted by Reinhoff $(70-a)$ and $70-d)$

55. Moll, H. and Scott, R.A.M.: Gastric Secretion in Greves, Disease., Lancet, 1:68, 1927.

56. Moore, H.: Significance of Achlorhyarie, Brtt. Med. J., I:689, 1930 .

57. Mora, J.M.: The Intracutaneous Selt-Solution Test in Thyrotoxicosis., Am. J. Med. Sci., 177:219$223,1929$.

58. Morris, R.S.: Thyrotoxicosis "Masked" by Normal or Subnormal Basal Metabolic Rate., Internat'l. clin., 3:64-67, 1933.

59. Nicholls, E.G.: The Surface Tension of Human Blood Under Normal and Pathological Conditions., Johns Hopkins Hosp. BuI., 42:358-395, 1928.

60. Nichols, B.H.: The Thyroid Gland, Crile, G.W. and associates, Phila. Saunders, 1922, p.129.

61. Novick, N.: Native complement in Hyperthyroidism, Arch. Int. Ned., 48:462, 1931.

62. Ormsby, 0.S.: Diseases of the Skin, Phila. Lea and Febiger, 1924, $p .1088$.

63. 0sgood, E. E.: A Pextbook of Laboratory Diagnosis, Phila. Blakiston, 1935, (a) pp.55,87, (b) p.39, (c) $\mathrm{p} .57$.

63A. Parry, C.H.: quoted by Philitps, (64-e)

64. Phillips, J.: The Thyroid Gland, Crile, G.W. and associates, Saunders Phila, 1922., (a) p.83,

(b) $0.83,(\mathrm{c}) \mathrm{p} .84$, (d) $\mathrm{p} .85,(\mathrm{e}) \mathrm{p} .49,(\mathrm{f}) \mathrm{p} .54$, (g) $p .86$.

65. Plummer, H.S.: Results of Administering Iodine to Patients heving Exophthalmic Goiter., J.A.N.A., $80: 1955,1923$. 
66. Plumer, H.S.: The Function of the Thyroid Gland Containing Adenomatous Tissue, Trans, Ass. Phys., $43: 159-164,1928$.

67. Plummer, N.A.: The Blood Picture in Exophthalmic Goiter, collected Papers of Mayo clinic, $10: 359-363,1918$.

68. Plurmer, W.A.: Some Phases of the Differential Diagnosis of Exophthalmic Golter., St. Paul H.J. $18: 297,1916$.

69. Plummer, H.S.: Blood Prescure and Thyrotoxicosis, Trans. Ass'n. Am. Phys., 30:450, 1915.

69A. Reisman, D.: Bruit Over the Eyeball in Exophthalmic Golter, J.A.M.A., $66: 1381$, 1916 .

70. Reinhoff, W.F.: Diseases of the Thyroid Gland, Dean Lewis, Practive of Surgery, 6: ohap. I, 1929. (a* p.26, (b) p.27. (c) p.42, (a) pp.101,102 (e) p.106, (f) p.108, (g) p.114.

71. Reinhoff, T.F.: A net Conception of Some horbid Changes Occurring in Disease of the Thyrold Gland Besed on Experimental studies of the Normal Gland and the Thyroid in Exophthalmic Goiter. Medioine $10: 257,1931$.

72. Rolleston, H.: Caleb Hillier Parry., Am. Med. Hist., N.Y. , 1925, 7:205-215

73. Rowe, R.T.: Studies of Endocrine Glands., Endoorinology, 13:342, 1929.

74. Rowe, R.W.: Tndocrine Diagnosis, Endocrinology, $12: 37,1928$.

75. Shirer, J.H.: Hypermotility of the Gestro-Intestinal Tract in Hyper thyroidism, An. J. Med. Soi., $186: 73-78,1933$.

76. Stellway, von, 0.0.: Ueber gevisse Innervationstorungen bei der Basedow'sche Krankheit, Med. Jahrb. Wien. 17:25-54, 1869, quoted by Reinhorf $(70-d)$.

76A. Suker, G.P.: A New ocular Muscle Symptom in Exophthalmic Goiter, J.A.M.A., 68:1255, 1917. 
77. Teussig, A.E.: Some Blood Pressure Phenomena in Exophthalmic Goiter, Tr. Ass'n. Am. Phys. $31: 121,1916$.

78. Tuoker, J.: Hyperthyroidism vithout Visible or Palpable Goiter, Am. J. Med. Sci., 176:510, 1928.

78A. Von Gragle: quoted by Hason (2l-a).

79. Welt-Kakels, S.: A Case of Exophthalmic Goiter, Med. Rec., 91:1161, 1917.

80. White, C.: A Fetus with congenital Hereditary Greves' Disease, Proc. Roy. Soc. Hed. Iond. 0. . Section. 5:247-250, 1911-1912.

81. Wilson, L.B.: The Heart in Exophthaimic Goiter and Adenoma with Hyperthyroidism, Hed. Clin. of No. Am., 7:189, 1923.

82. WohI, M.G.: Masked Hyperthyroidism, Med. Clin. No. Am., 16:121-142, 1932.

82A. Tolpe: Hospitalstidende, 62:1914, quoted by Lockmood, 48 .

83. Yung, J.R.; Toxic Diffuse Goiter, J. Indiana Med. Ass'n., 2:172-174, April, 1936.

84. Zimmerman, I.M.: Exophthalmos Following Operation for the Rolief of Hyperthyroidism., Am. J. Med. Sci., $178: 92,1929$. 